\title{
A Methodology for Modelling of Steady State Flow in Pelton Turbine Injectors
}

\author{
Tri Ratna Bajracharya ${ }^{1,2^{*}}$, Rajendra Shrestha ${ }^{1}$, Ashesh Babu Timilsina ${ }^{1,2}$ \\ ${ }^{1}$ Department of Mechanical Engineering, Pulchowk Campus, Institute of Engineering \\ Tribhuvan University, Nepal \\ ${ }^{2}$ Center for Energy Studies, Institute of Engineering, Tribhuvan University, Nepal \\ Corresponding author: "triratna@ioe.edu.np
}

Received: May 20, 2019

Revised: July 2, 2019

Accepted: July 5, 2019

\begin{abstract}
Pelton turbine is a high head-impulse type turbine. The high-speed jet strikes the symmetrical semi ellipsoidal buckets, thus transferring the momentum within short period of time, impulse. The conversion of potential energy of water to kinetic energy in the form of jet is done by a nozzle with internally fitted spear or needle, the assembly in known as injector. The jet quality includes but is not limited to jet velocity, velocity distribution 'velocity profile', core location etc. In this study, the modeling of flow in Pelton turbine injector is done by commercial Computational Fluid Dynamics (CFD) solver on a three-dimensional flow domain. The results obtained from CFD modelling are then compared against the experimental observations and previously published literatures. The jet streamline, jet velocity profile and jet core location are then studied. As observed experimentally, the mean jet diameter reduces as the nozzle opening decreases. In addition, like the experimental observations, the jet first contracts and then expands. The diameter of the contraction is then normalized with nozzle exit diameter and is plotted for both experimental observations as well as the results of the numerical simulation. The maximum error between experimental and numerical analysis of jet contraction is $20 \%$. The jet core is located at region axially ahead of needle tip.
\end{abstract}

Keywords: Pelton turbine injector-CFD Modeling-Jet Contraction

\section{Introduction}

Selection of hydro turbine for a particular site depends upon the head and flow condition [1]. Fig. 1 shows the application ranges of various types of hydraulic turbines. It can be seen that Pelton turbine is employed in high head sites. The choice of turbine in the overlapping region is done by techno-economic analysis. Factors to be considered during the selection may be part load efficiency, fall of efficiency, response to erosion, size of generating units, cost factors etc. A brief review of salient features of large hydro power plant $(>30 \mathrm{MW})$, shows that Pelton turbine is most commonly used Impulse turbine. Being a high head impulse turbine, Pelton turbine works by harnessing the power of water by first converting the entire potential energy of the water to kinetic energy in the form of a jet. The conversion of the potential/pressure energy of the water to kinetic energy is done by the nozzle, inside which a spear (or needle) is fitted which changes the 
effective area of the nozzle for water exit $[2,3]$ all relevant flow processes and hydraulic aspects in a Pelton turbine have been analyzed completely and systematically. The analyses especially include the quantification of all possible losses existing in the Pelton turbine and the indication of most available potential for further enhancing the system efficiency. As a guideline the book therefore supports further developments of Pelton turbines with regard to their hydraulic designs and optimizations. It is thus suitable for the development and design engineers as well as those working in the field of turbo machinery. Many laws described in the book can also be directly used to simplify aspects of computational fluid dynamics (CFD. The assembly of nozzle and needle is understood as injector. The jet then strikes symmetrical bucket, which splits the jet into two semi ellipsoidal cup. The change of momentum of the jet within a very short time creates impulse in runner bucket. Bucket, runner and nozzle are major factors that affect the performance of a Pelton turbine [4]. Previous to advancements in computational techniques and modelling capacity, manufacturers rely on experimental tests only to know about flow and performance of hydraulic machinery. Modern day Pelton turbines are highly efficient machines. Present advancement in Computational Fluid Dynamics (CFD) has enabled one to better predict the flow phenomenon.

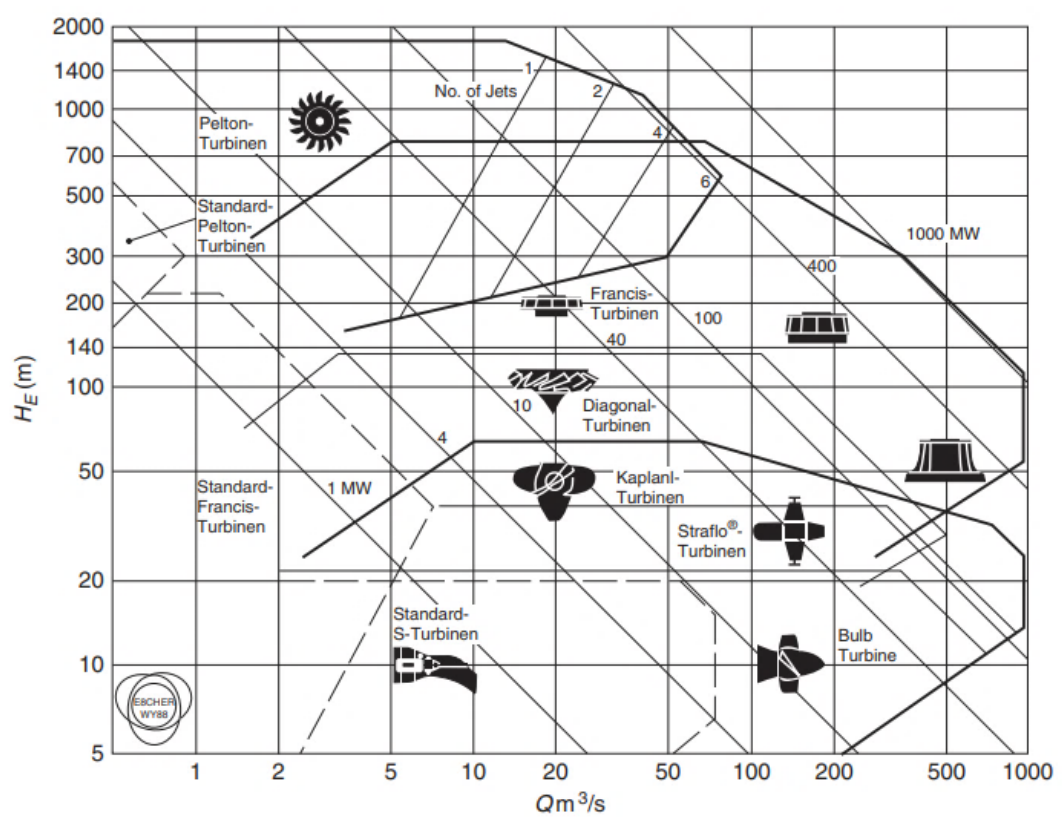

Fig. 1: Turbine Selection Nomogram [5]

Jet velocity, Velocity distributions, Jet diameter are commonly categorized under the heading of jet quality $[6,7,8]$ for the first time, experiments and numerical simulation were conducted to investigate the effect of the spear needle eccentricity on the jet flow in micro Pelton turbines. Results show that the eccentricity of the spear needle causes jet diffusion under low flow conditions and significantly increases the loss of the spear nozzle (injector. The parameters under jet quality is known to alter the performance of the Pelton turbine and authors have experimentally and numerically studied about the influence. An ideal jet is supposed to have uniform velocity distribution in each cross section and the jet diameter is assumed to be constant without any contraction or expansion [9]. Experimental investigations by photographic observations [10] and Laser Doppler Anemometry 
[11] of the jet reveals that the real jet deviates from this ideal form. It is seen that the jet after its exit from the nozzle first contracts and attains a minimum diameter, known as vena contracta, then it expands. In this study, the flow in micro Pelton turbine injector is modelled using commercial CFD code for different nozzle opening (four cases are modeled) and the phenomenon of jet contraction, expansion is studied along with axial velocity distribution of the jet.

\section{Methodology}

A schematic diagram of typical injector used for micro Pelton turbines is shown in Fig. 2. The flow domain is modeled in Three-Dimensional Computer Aided Design (3D CAD) software and then discretized (meshed) using ICEM. The mesh is then exported to the commercial CFD solver with boundary conditions defined. The turbulence model used is the realizable k-epsilon model based on the previously published literatures. The solution for flow is obtained with convergence criterion of $10^{-6}$ for all governing equations including the turbulence model. Flow streamline, jet velocity distribution (velocity profile) was studied in the post processing. The flow streamline is then further analyzed for quantitatively studying the jet contraction and expansion phenomenon. The control volume and geometrical specifications of the flow domain is summarized in Fig. 3.

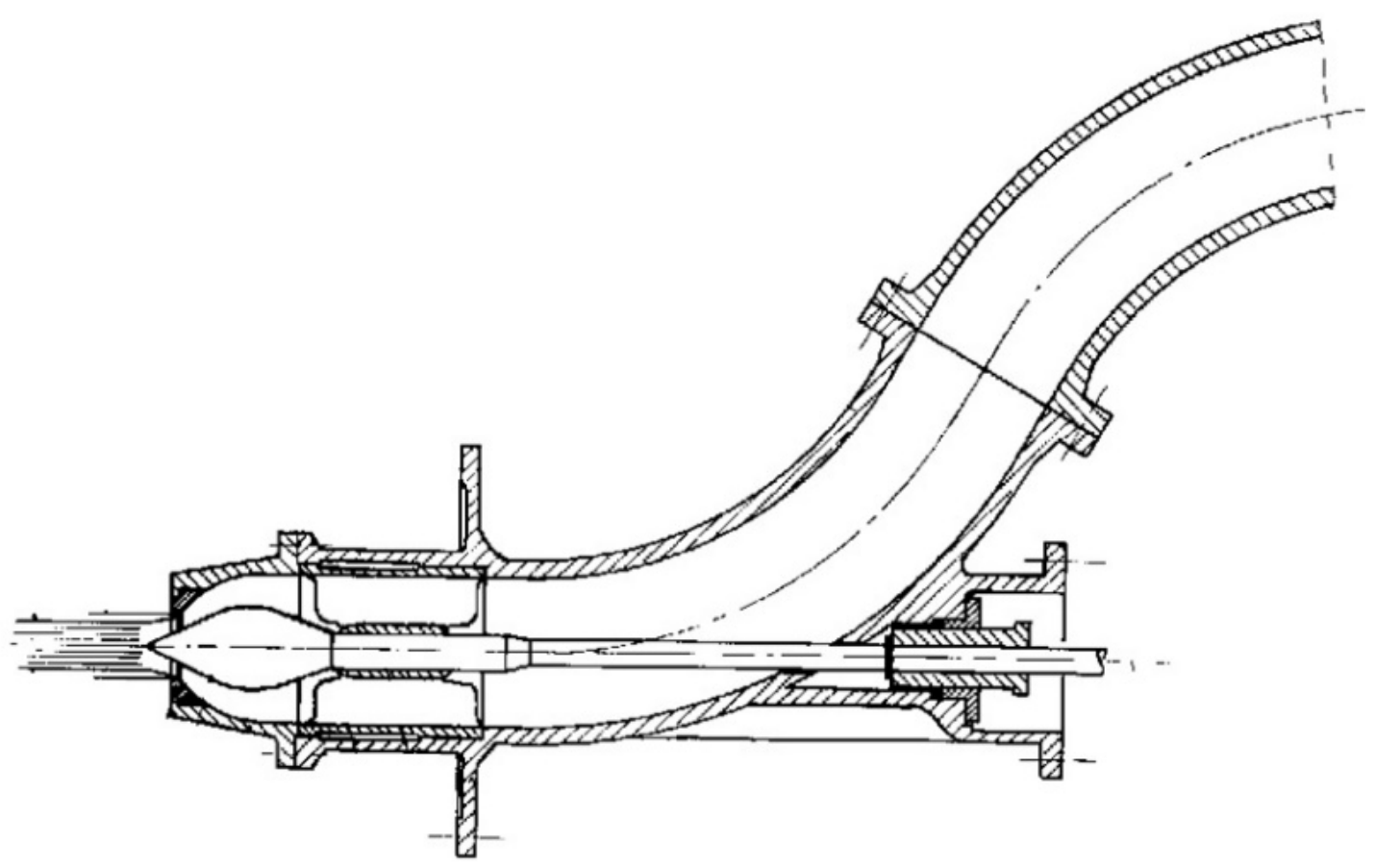

Fig. 2: General Schematic Diagram of Pelton Turbine Injector [12]

The flow domain used in this study is the injector of a $2 \mathrm{~kW}$ model Pelton turbine. The Pitch Circle Diameter (PCD) of the runner is $175 \mathrm{~mm}$ and the jet opening is $20 \mathrm{~mm}$. Fig. 3 summarizes the geometrical specifications of the domain. 


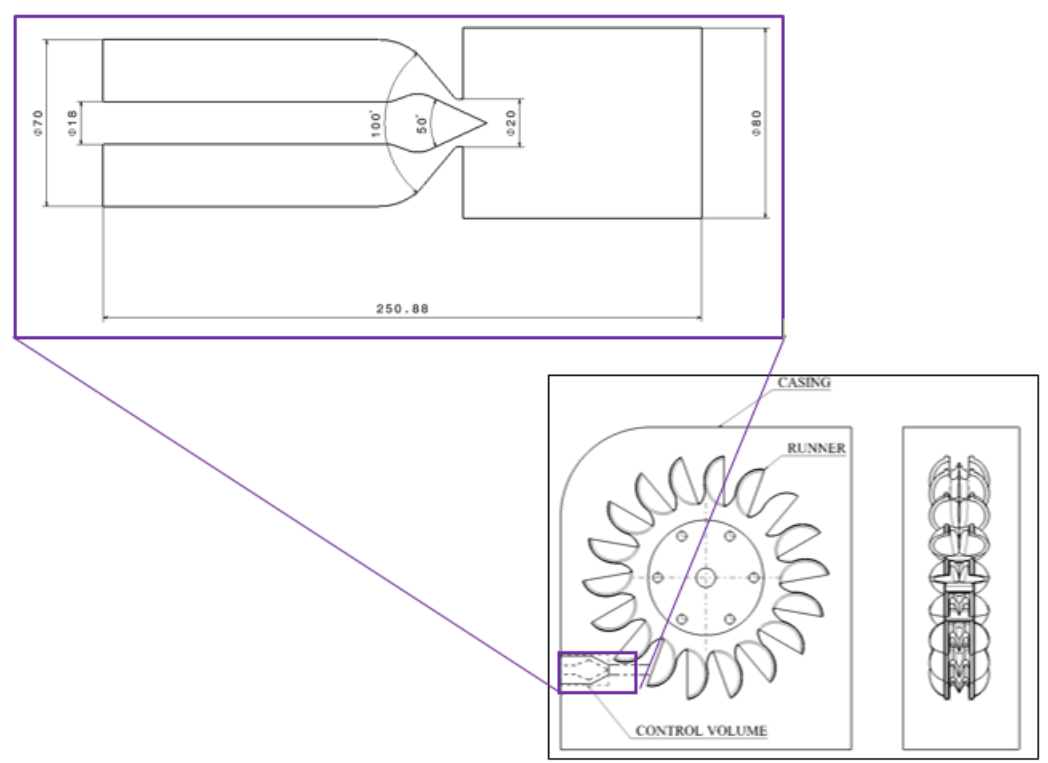

Fig. 3: Control volume and flow domain

The boundary conditions used for CFD modelling is presented in Fig. 4. To better capture the viscous layer effects, the fine mesh was used in the needle wall and in the nozzle wall. The axially symmetric nature of the flow domain made the choice of O-grid optimum in this case.

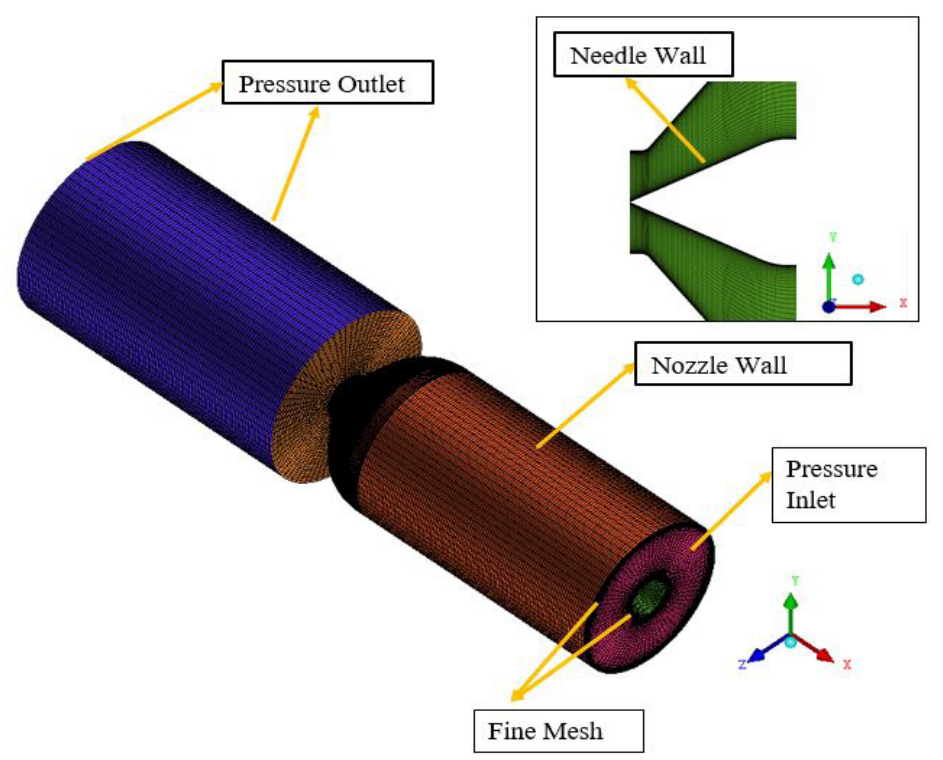

Fig. 4: Boundary Conditions

The numerical value at pressure inlet was set at 3 bar (gauge) while the pressure outlet was assigned value of 0 bar (gauge). The solver settings used is summarized in table 1. 
Table 1: Summary of Solver Settings

\begin{tabular}{|c|c|}
\hline Solver & Three-Dimensional, Steady State, Pressure Based \\
\hline Time discretization & Steady State \\
\hline Discretization scheme & Second Order \\
\hline Turbulence model & Realizable $k$-epsilon \\
\hline Convergence criteria & RMS, Scaled residual target $=10^{-6}$ \\
\hline Hardware & Processor: Intel Core i7 @ 3.6 GHz (8 CPUs). Memory: $32 \mathrm{~GB}$ \\
\hline
\end{tabular}

\section{Results and Discussion}

\section{a. Mesh Independency Test}

Numerical simulation is always associated with discretization error, but use of very fine discretization requires high computation time. Hence, it is desired to have an economic discretization (mesh size) of the study domain with minimal discretization error and optimal solution time. Mesh independency test ensures that the mesh generated after domain discretization gives solution with minimal error i.e. with further dense mesh, the change in solution is considerably small. After $6^{\text {th }}$ iteration of fine mesh for half open nozzle, the error with previous simulations were less than $1 \%$, hence, the mesh with 15,164,524 nodes was accepted. The parameter of interest was the maximum velocity at distance $40 \mathrm{~mm}$ ahead of nozzle exit (the position where the jet strikes the runner bucket). Fig. 5 shows the summary of test done. The overall error in prediction is compared with the experimentally measured velocity.

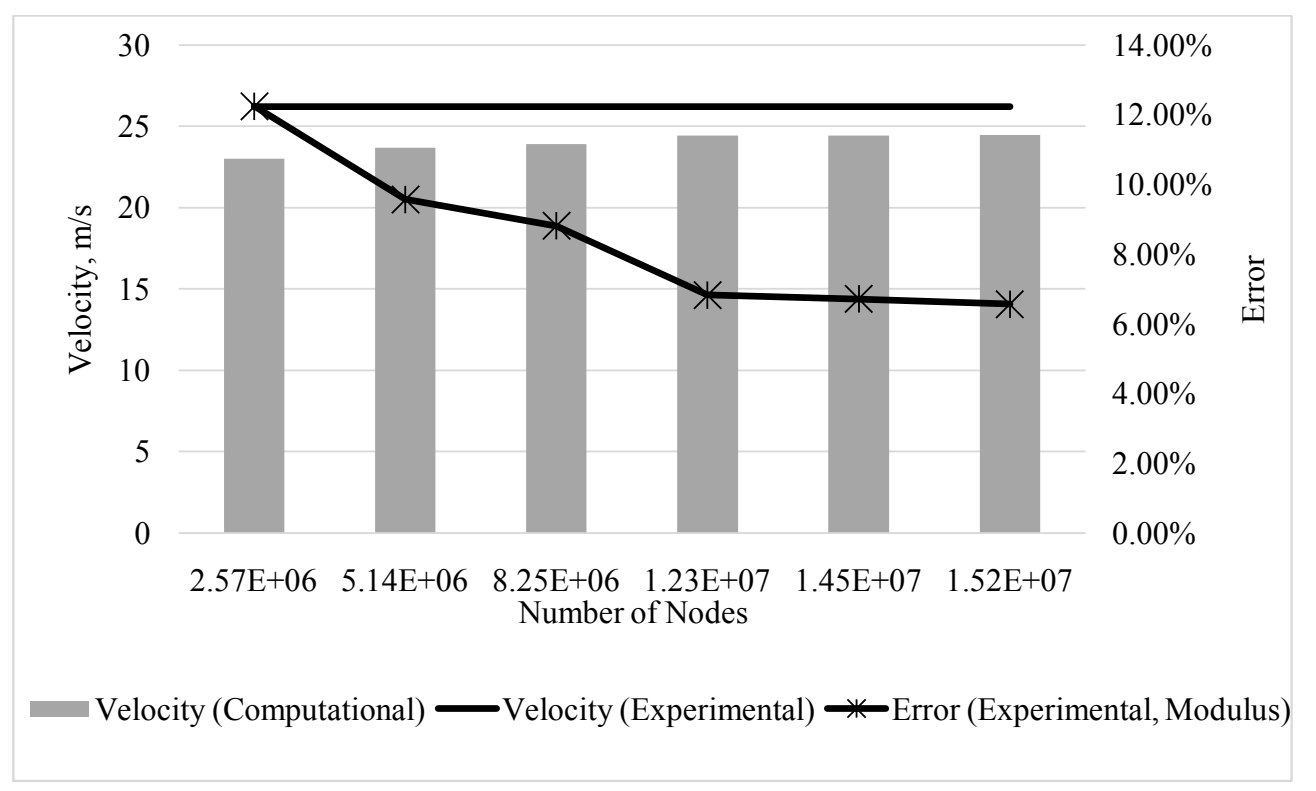

Fig. 5: Mesh Independency Test

Fig. 6 presents the flow field after solution convergence for the half open nozzle $(50 \%$ nozzle opening). 

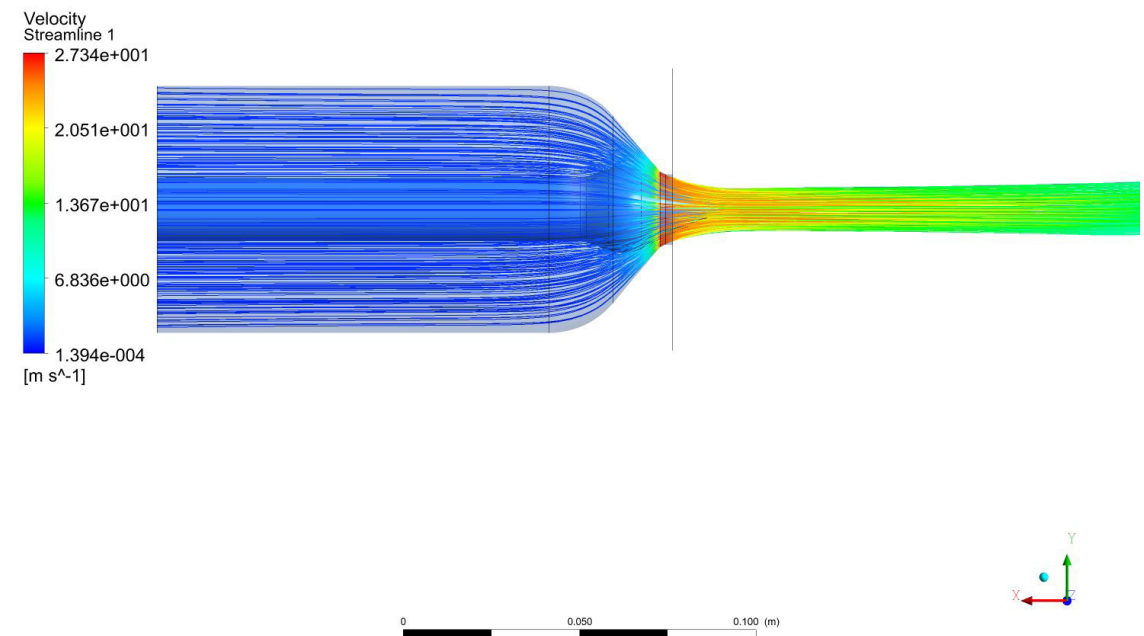

Fig. 6: Jet streamline for half open nozzle

The similar edge distribution for meshing was the used for nozzle opening of $100 \%, 90 \%$ and $80 \%$. Flow field visualization

Table 2 presents the comparison of flow pattern for different nozzle opening obtained from numerical simulations and experimental results obtained by photographic observations in [10]. The contraction of jet with reduction in nozzle opening can be seen with both cases. The jet follows the needle surface during course of contraction which can be explained by Coanda effect, which states that due course of fluid flow if there is interaction of fluid with solid surface, the fluid follows solid surface.

The detailed analysis of jet contraction and expansion is also done. A case for $80 \%$ nozzle opening is presented in Fig. 7.

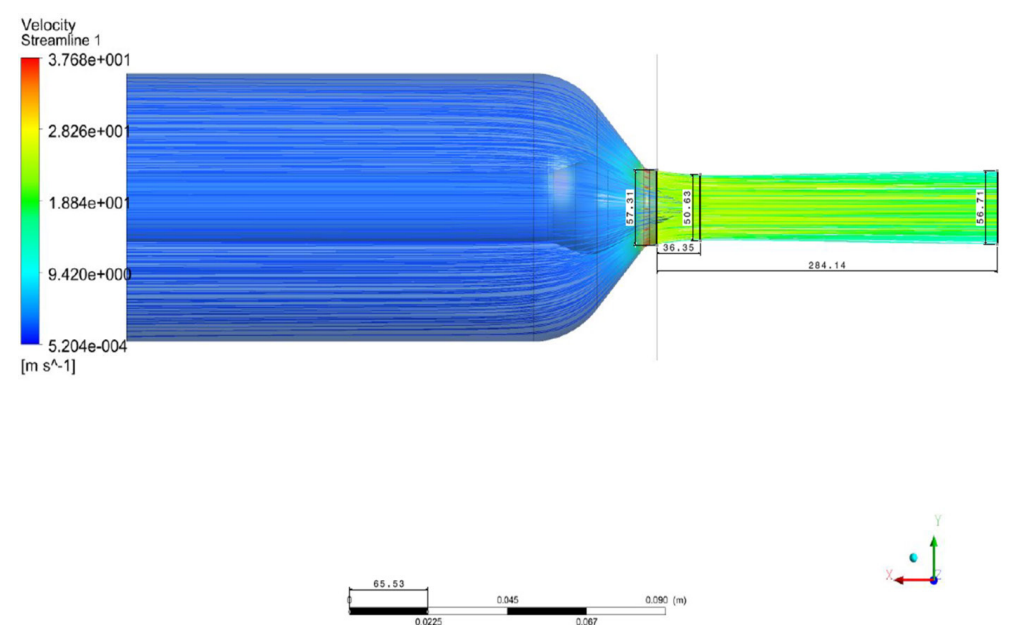

Fig. 7: Streamlines for $80 \%$ Nozzle Opening 
Table 2: Flow Comparison

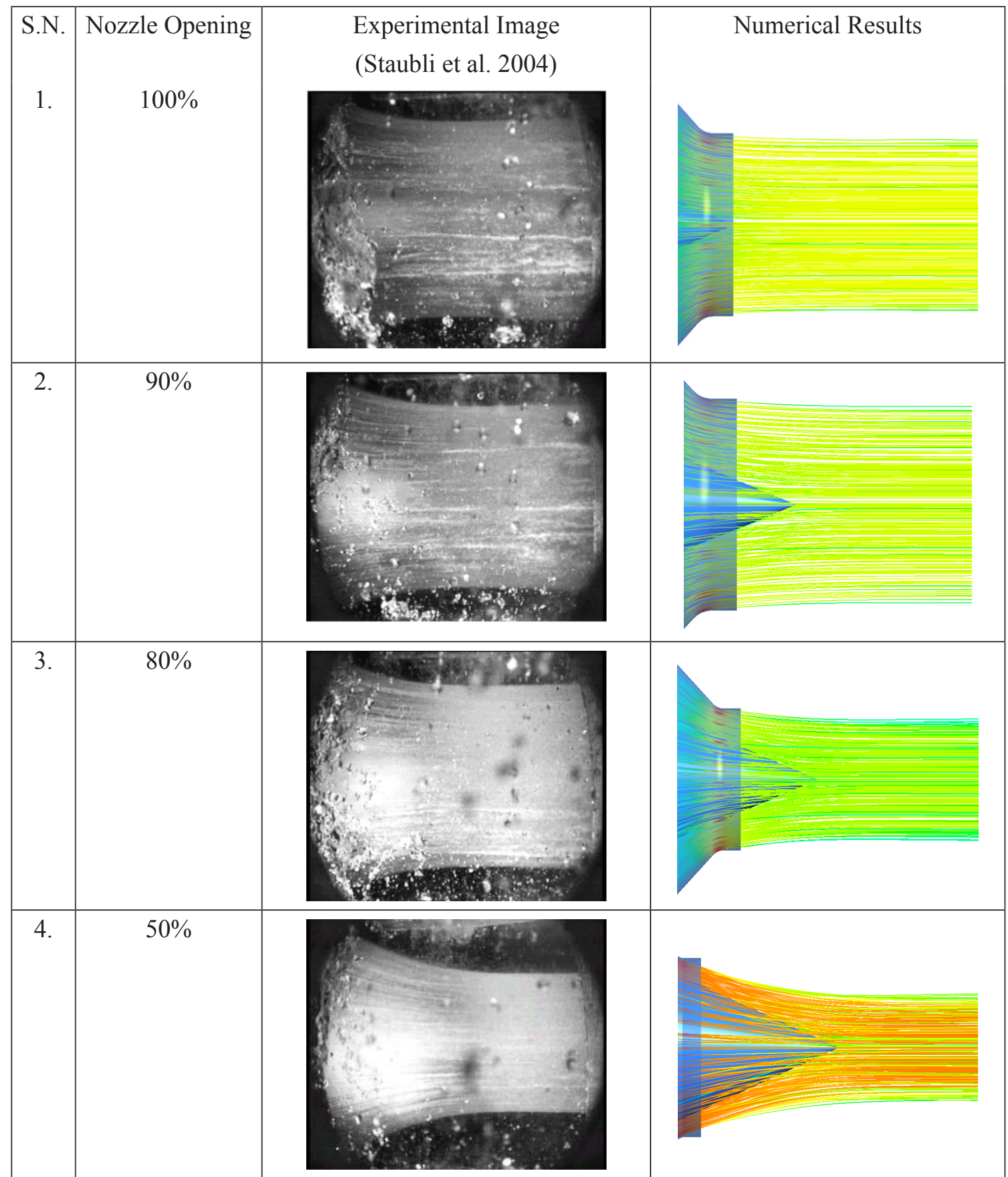

The measurements of the jet for $80 \%$ nozzle opening is done and is tabulated in Table 3 . 
Table 3: Flow Analysis for Nozzle Opening $=\mathbf{8 0} \%$

\begin{tabular}{|c|c|c|}
\hline In Figure 6 & Actual & Remarks \\
\hline 65.53 & 0.0225 & Scale \\
\hline 57.31 & 0.020 & Jet Opening \\
\hline 50.63 & 0.017 & Diameter at vena contracta \\
\hline 56.71 & 0.019 & Diameter of expanded jet \\
\hline 284.14 & 0.098 & Measured position of jet expansion \\
\hline 36.35 & 0.012 & Measured position of jet contraction \\
\hline Contraction & $-11.66 \%$ & Coefficient of Contraction (Normalized to nozzle diameter) \\
\hline Expansion & 0.10 & Expansion Angle (in degrees) \\
\hline
\end{tabular}

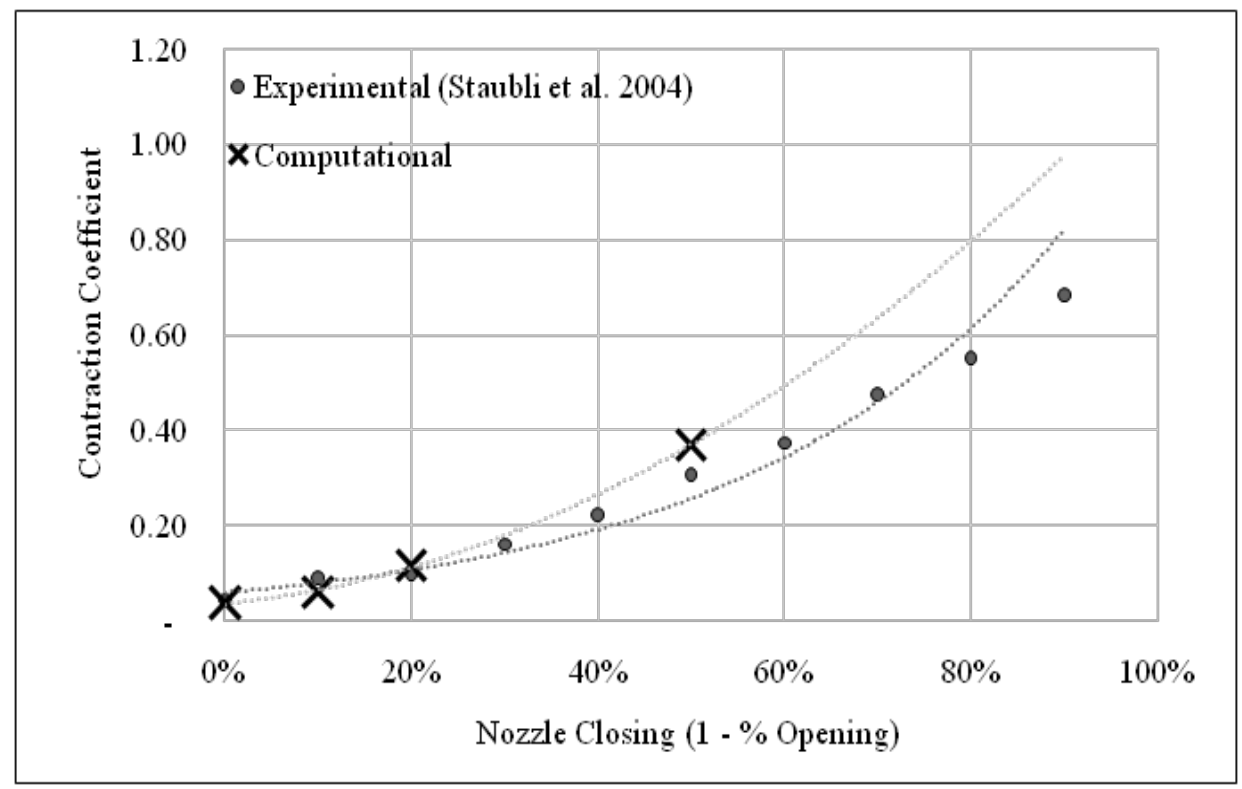

Fig. 8: Jet contraction trend analysis

The analysis of streamlines was done for fully open condition of nozzle, nozzle opening of $90 \%$ and $50 \%$ as well. The plot of jet contraction was then done and superposed with the contraction analyzed from experimentally obtained images. As seen from Fig. 8, the trend of computational analysis follows the experimentally obtained trend.

The experimental measurement of the jet velocity was done by measurement of the runner speed. Table 4 presents about the error calculation. For all the measured cases, the runner speed did not change significantly, thus, here for the purpose of error calculation, the average measured runner speed is considered. 
Table 4: Error Calculation

\begin{tabular}{|c|c|c|c|}
\hline \multicolumn{4}{|c|}{ Calculation of Jet Velocity } \\
\hline S.N. & Item & Value & Units \\
\hline 1 & Runner PCD & 0.175 & $\mathrm{~m}$ \\
\hline 2 & Measured Runner RPM & 1430 & RPM \\
\hline 3 & Linear speed of Bucket & 13.10 & $\mathrm{~m} / \mathrm{s}$ \\
\hline 4 & Assuming maximum eff. Condition, Jet Velocity & 26.21 & \\
\hline \multicolumn{4}{|c|}{ Error analysis for Different Needle Strokes } \\
\hline \multicolumn{4}{|c|}{$\begin{array}{c}\text { Velocity From Computations as measured at location of runner bucket, the point where Jet and Bucke } \\
\text { Interact }\end{array}$} \\
\hline \multirow{2}{*}{1} & For Needle Stroke $=0 \mathrm{~mm}$, Velocity & 24.5 & $\mathrm{~m} / \mathrm{s}$ \\
\hline & Error in Computation & $-6.51 \%$ & \\
\hline \multirow{2}{*}{2} & For Needle Stroke $=5 \mathrm{~mm}$, Velocity & 24.4 & $\mathrm{~m} / \mathrm{s}$ \\
\hline & Error in Computation & $-6.89 \%$ & \\
\hline \multirow{2}{*}{3} & For Needle Stroke $=10 \mathrm{~mm}$, Velocity & 24.4 & $\mathrm{~m} / \mathrm{s}$ \\
\hline & Error in Computation & $-6.89 \%$ & \\
\hline \multirow{2}{*}{3} & For Needle Stroke $=15 \mathrm{~mm}$, Velocity & 24.5 & $\mathrm{~m} / \mathrm{s}$ \\
\hline & Error in Computation & $-6.51 \%$ & \\
\hline
\end{tabular}

Analysis and comparison of velocity at two different section for four different nozzle opening is presented in figure 9. The normalized velocity profile matches with those published in [2], [11].

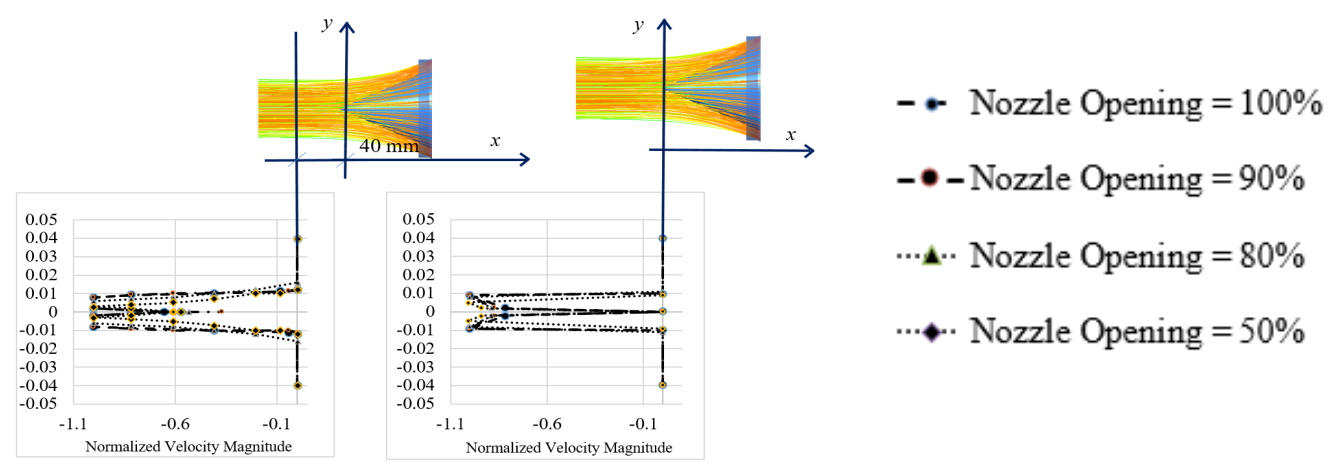

Fig. 9: Jet Velocity (Normalized) for Different Needle Strokes

The jet velocity is normalized with maximum jet velocity (negative sign corresponds to negative $\mathrm{x}$-axis). Fig. 9 is the plot of normalized velocity against radial position for two different axial position (first at needle tip and second at distance $40 \mathrm{~mm}$ ahead of nozzle exit, the location where jet strikes runner). As seen from Fig. 9, the jet core is in the region axially ahead of the needle tip. And the jet core is the region of minimum velocity across the jet which is zero at the needle tip. Experimental observations [11] of the jet shows that the jet core finally disappears with all jet having uniform velocity at distance, 8 times of nozzle diameter. 


\section{Conclusion}

The flow analysis on Pelton turbine injector was done using commercial three-dimensional computational fluid dynamics solver and the results obtained are compared with experimental observations as well as with the previously published experimental literature. The jet contraction phenomenon was observed for the free surface jet exiting from the nozzle. The jet, contracts forming a minimum diameter region 'often known as vena contracta' and afterwards expands. Also, with the decrease in Nozzle opening, the jet diameter decreases. The comparison of jet contraction against various nozzle opening are in good agreement. The error in computation of the jet velocity from CFD in comparison to experimental one is $6.89 \%$. The normalized velocity profile obtained from CFD modeling shows zero velocity at needle tip and the minimum velocity area across the jet is the region axially ahead of the needle tip.

Acknowledgements: The authors are grateful to University Grants Commission, Sanothimi, Bhaktapur for funding this research under faculty research grant (FRG-74/75-Engg-04). The authors would like to acknowledge technical support from Center for Energy Studies, Institute of Engineering, Chilime Hydropower Plant and Robotics Club, Pulchowk Campus.

\section{References}

[1] Thapar OD (2002), Modern Hydroelectric Engg Practice. Alternate Hydro Energy Center, Indian Institute of Technology Roorkee.

[2 ] Zhang Z (2016), Pelton turbines, 1st ed. Switzerland: Springer International Publishing.

[3] Bajracharya TR, Acharya B, Joshi CB, Saini RP and Dahlhaug OG (2008), Sand erosion of Pelton turbine nozzles and buckets: A case study of Chilime Hydropower Plant, Wear 264 (3-4): 177-184.

[4] Židonis A and Aggidis GA (2015), State of the art in numerical modelling of Pelton turbines, Renew. Sustain. Energy Rev 45: 135-144.

[5] Dixon SL and Hall CA (2010), Fluid mechanics and thermodynamics of turbomachinery. Butterworth-Heinemann/Elsevier.

[6] Peron M, Parkinson E, Geppert L and Staubli T (2008), Importance of jet quality on Pelton efficiency and cavitation, in: International Conference on Hydraulic Efficiency Measurements (IGHEM) 2008.

[ 7 ] Jo IC, Park JH, Kim JW, Shin Y and Chung JT (2016), Jet quality characteristics according to nozzle shape of energy-recovery Pelton turbines in pressure-retarded osmosis, Desalin. Water Treat, 57(51): 24626-24635.

[ 8 ] Jung IH, Kim YS, Shin DH, ChungJT and Shin Y (2019), Influence of spear needle eccentricity on jet quality in micro Pelton turbine for power generation, Energy, 175: 58-65.

[9] Zhang Z (2016), Working Principle of Pelton Turbines, Pelton Turbines, Cham: Springer International Publishing: 13-28.

[10] Staubli T and Hauser HP (2004), Flow visualization - a diagnosis tool for Pelton turbines 1: $1-9$.

[11] Zhang Z and Casey M (2007), Experimental studies of the jet of a Pelton turbine, in: Proc. Inst. Mech. Eng. Part A J. Power Energy 221 (8): 1181-1192.

[12] Micro Pelton Turbines: 3 Components and Design Principles: 3.4 Nozzle, Online Available: http://www.nzdl.org/gsdlmod [Accessed: 25-May-2019]. 